\title{
Uncovering configurations of HRM service provider intellectual capital and worker human capital for creating high HRM service value using fsQCA
}

\author{
Jeroen Meijerink*, Tanya Bondarouk \\ University of Twente, Drienerlolaan 5, 7522 NB Enschede, The Netherlands
}

\section{A R T I C L E I N F O}

\section{Keywords:}

Intellectual capital theory

Consumer perspective

Value

Configurations

Human resource management

Service Dominant Logic

\begin{abstract}
A B S T R A C T
Although traditionally applied independently, this study combines two theoretical perspectives - the intellectual capital theory and the consumer perspective - to uncover value-creating configurations of human resource management (HRM) service providers' and workers' knowledge resources. We examined workers' perceptions of the value of provided HRM services using data from a sample of more than 2000 workers and the HR professionals that serve them. Using fuzzy set qualitative comparative analysis techniques, we found that the HRM provider's intellectual capital is a necessary, but not always sufficient, condition for high HRM service value. Further, our results show that workers can fulfil a 'substitute for competence role' when they rely on their own well-developed knowledge and skills to substitute for HRM professional inabilities. Accordingly, this study highlights the need for studying value co-creation in HRM research, that is, how both HR professionals' and workers' attributes and actions interrelate for explaining the outcomes of HRM services.
\end{abstract}

\section{Introduction}

The provision of services is often associated with a firm's services for external customers. However, many so-called support functions within a firm offer their services to internal customers (i.e. workers) who receive internal support services such as procurement, information management, and housing services. Research has cumulated evidence which shows that the value of internal support services to workers is positively associated with worker retention (Wildes \& Parks, 2005) and service quality for external customers (Schneider, White, \& Paul, 1998). Of all internal services, we see the value of human resource management (HRM) services as one of the most significant as it adds to workers' organizational commitment (Gilbert, De Winne, \& Sels, 2011) and performance (Edgar \& Geare, 2014). Therefore, in this paper we study HRM service value for workers, which is defined as the perceived quality versus costs of HRM services, provided to workers by an HRM service provider internal to the firm.

Extant research relied on two different theoretical perspectives to identify two primary conditions that drive value creation: the intellectual capital of the provider (in our case: an HRM service provider that employs a collective of HRM professionals who offer HRM services to workers) and the human capital of the recipient (in our case: workers who receive and make use of HRM services). The first perspective intellectual capital theory - proposes the knowledge resources that a service provider develops, shares and codifies as a critical determinant of service value (Reed, Lubatkin, \& Srinivasan, 2006; Youndt, Subramaniam, \& Snell, 2004). The other perspective - the consumer perspective - focuses on the human capital of service recipients, that is, their knowledge, skills and abilities to effectively utilize and thus create value out of a service (Priem, 2007). In HRM research, both perspectives have been applied independently to show that the intellectual capital of HRM service providers as well as human capital of workers i.e. internal recipients of HRM services - is associated with high HRM service value as perceived by workers (Boselie \& Paauwe, 2005; Meijerink, Bondarouk, \& Lepak, 2016).

In this paper we argue that our understanding of HRM service value improves when combining both perspectives as it allows to remedy some of the inconsistencies associated with each perspective. Namely, intellectual capital theorists largely overlooked service recipients (including workers) in the analysis of knowledge utilization for value creation. The consumer perspective complements intellectual capital theory in this respect, by highlighting consumer human capital as a factor that enables service recipients to effectively utilize the resources provided (Priem, 2007). At the same time, the consumer perspective remains silent on the resources that would support providers in improving the human capital of service recipients (Meijerink et al., 2016; Priem, 2007). Here, intellectual capital theory complements the consumer perspective by proposing provider knowledge resources for strategy enactment.

This study aims to examine the complementarity mechanisms

\footnotetext{
* Corresponding author.

E-mail addresses: j.g.meijerink@utwente.nl (J. Meijerink), t.bondarouk@utwente.nl (T. Bondarouk).
} 
between the intellectual capital and consumer perspectives. We do so by exploring value-adding configurations of the intellectual capital of HRM service providers and human capital of workers. This configuration analysis allows us to make three important contributions. First, it allows us to introduce and differentiate between the necessity and sufficiency of consumer human capital and provider intellectual capital to produce high service value. According to configuration theorists (Fiss, 2011) this is important as it helps resolving inconsistencies in observed correlation effects. Namely, besides finding positive effects, existing research also showed that intellectual capital of HRM service providers and human capital of workers can be insignificantly correlated to HRM service value (Boselie \& Paauwe, 2005; Meijerink \& Bondarouk, 2013). Our configuration analysis compares the necessity and sufficiency of provider and recipient resources to provide an explanation for these observed inconsistencies.

Second, we examine whether provider intellectual capital and consumer human capital synergize or substitute in creating configurations that are sufficient for creating high service value. Since, in the past, the intellectual capital and consumer perspectives have been individually and separately applied, we do not know what "happens" inside configurations where the two theories meet. Gaining this knowledge will help to further uncover observed inconsistencies while it provides insights into how provider intellectual capital and consumer human capital each represent a condition against which the other can impact on service value.

Finally, although existing HRM studies build on configuration theory's equifinality principle (Delery \& Doty, 1996), they found it challenging to empirically test this principle (Renkema, Meijerink, \& Bondarouk, 2016). The principle of equifinality applies exclusively to open systems, as opposite to closed systems where processes occur in machine-like structures and follow a fixed pathway. While HRM services have been regarded as open systems, HRM researchers have limitedly studied the equifinality of paths that lead to HRM outcomes. This is understandable as the notions of high quality resources (knowledge, skills and abilities) do not lend easily to quantitative interpretations. We took the challenge to empirically showcase the equifinality principle where multiple configurations of service provider and recipient resources are equally effective for creating high value of HRM services. For this challenge we use a relative new methodology: fuzzy set qualitative comparative analysis (fsQCA).

\section{Theoretical background and hypotheses}

\subsection{HRM service value for workers}

In this study, the focal outcome variable is the value of internal HRM services (or: HRM service value). HRM services are provided by intra-organizational units such as corporate HR departments, HR shared service centres and centres of HR expertise (Farndale, Paauwe, \& Hoeksema, 2009; Ulrich, Younger, \& Brockbank, 2008). The majority of these units employ multiple HRM professionals who are jointly responsible for providing workers with HRM services such as payroll administration, personnel record keeping and training. On this basis, we refer to a provider of HRM services as a collective of HRM professionals that work within an intra-organizational unit that is tasked with providing HRM services to workers (Maatman, Bondarouk, \& Looise, 2010).

The notion of value has stimulated a significant debate among HRM scholars, and as Lepak, Smith, and Taylor (2007) observed, "considerable disagreement and confusion remain among scholars on the nature of value creation" (p. 190). Entire papers have been dedicated to examining value, adding even more confusion to the subject (Barney \& Clark, 2007; Bowman \& Ambrosini, 2007; Kaufman, 2015). Proponents of the Resource Based View (RBV), for example, define value as "the difference between perceived benefits, or customer willingness-to-pay, (...) and economic costs" (Barney \& Clark, 2007: 25).
Kaufman (2015) explains it as the RBV sees value as a total surplus that is divided between the firm (who "sells") and customer (who "buys"). Considerations from the Strategic Factor Market imply that in perfect competition, prices are shaved away until they just cover firm's production costs (Kaufman, 2015), and thus, total value created by a firm, is fully distributed to consumers.

Certainly, HRM scholars are aware of these notions from the strategic management field. However, so far the HRM research field develops through an ongoing repetitive wheel in an attempt to integrate discussions about the strategic value of HRM services that has centred around various concepts such as effectiveness, firm performance and competitive advantage (see for an overview, Kaufman, 2015). The ten year old definition of value suggested by Lepak et al. (2007) brings these concepts together in an integrated definition of value as a difference between use value (i.e. the quality for the service recipient) and exchange value (i.e. price of the product or service). At the same time, this conceptualization also falls short as it ignores the firm's surplus. Bowman and Ambrosini (2007) seem to resolve this issue. Their suggestion is to keep the differences between quality and costs but to differentiate measures of value across firms' stakeholders. They suggest that total value should be accommodated from value to customers, value to workers, and value to firm.

From the discussion above, we narrow our conceptualization of HRM service value as the quality versus costs of HRM services as perceived by a worker. As such, we stress the service management perspective that emphasizes the importance of perceptions of value by a recipient (Blocker, 2011). Here, recipients refer to the workers that receive and make use of HRM services such as payroll administration, personnel record keeping and training (Meijerink et al., 2016).

Our conceptualization highlights two important features of service value. First, HRM service value is seen as a surplus such that the value of HRM services increases when workers perceive that their quality increases and/or costs decreases. Previous studies have found that service quality, in an HRM setting, is a multidimensional construct that consists of the quality of HRM service products (including the responsiveness and reliability of HRM services) and the quality of HRM service processes (including the empathy and assurance of HRM services) (Gilbert et al., 2011; Meijerink et al., 2016). In service marketing research, the costs of services have been conceptualized as monetary costs - i.e. the price paid by service recipients for acquiring a service - plus non-monetary costs - i.e. the time, effort and energy recipients spend to co-produce and consume a service (Blocker, 2011). In general, when receiving HRM services, workers do not pay a fee and, therefore, it is unlikely that they experience HRM services as having a monetary cost. Nevertheless, workers are involved in the delivery of HRM services and therefore they do experience non-monetary costs when they spend time, effort and energy on, for example, attending a training, applying for secondary benefit packages or administering personnel records (Meijerink et al., 2016). On this basis, we consider the costs of HRM services for workers to be non-monetary in nature and see them as the time, energy and effort spent by workers during the delivery/use of HRM services.

Second, our definition highlights that the value of HRM services reflects a perception held by a worker. This is in line with the idea that each individual service recipient can have a personal and highly idiosyncratic view on the value of a service which can deviate from the actual quality and/or cost of a service (Priem, 2007). Furthermore, as discussed before, different stakeholders - such as external consumers, workers and shareholders - experience value differently while they have different interests (Bowman \& Ambrosini, 2007). HRM research provides empirical support for the idea to conceptualize the value of HRM services as a perception of quality versus costs held by a worker. Namely, it shows that workers who perceive HRM services to be of high-quality are more committed to the organization and perform better than those who experience low HRM service quality (Edgar \& Geare, 2014; Gilbert et al., 2011; Wildes \& Parks, 2005). Also, 
workers have different experiences of the non-monetary costs of HRM services, depending how much time and effort they perceive to spent on, for example, acquiring HR-related information, operating HRM processes or applying HRM practices in their day-to-day activities (Bondarouk, Ruel, \& van der Heijden, 2009). In line with the conceptual and empirical insights discussed above, we study the value of HRM services as the perceived quality versus non-monetary costs of HRM services to a worker.

\subsection{Intellectual capital of HRM service providers}

Intellectual capital, which represents the knowledge, skills and abilities that a service provider draws on in value creation processes, is considered one of the key determinants of service value (Reed et al., 2006; Youndt et al., 2004). An important aspect of this definition is the idea that value does not come from the mere possession of knowledge, skills and abilities but, rather, that knowledge only creates value when it is utilized. This stresses that knowledge has to be put to use in value creation processes before it can be considered intellectual capital. In an HRM environment, HRM service providers draw on knowledge resources which are possessed by individual HR professionals, shared among individual HR professionals and codified in processes, protocols or online databases (Boselie \& Paauwe, 2005; Meijerink, Bondarouk, \& Looise, 2013; Ruta, 2009a, b). Therefore, we follow others (Reed et al., 2006; Youndt et al., 2004) by conceptualizing the intellectual capital of HRM service providers into three dimensions: human capital; social capital; and, organizational capital.

\subsubsection{Human capital of HRM service providers}

Human capital reflects the knowledge, skills and abilities of individuals employed by the service provider (Youndt et al., 2004). In an HRM environment, these individuals are HR professionals who work in HR service provider units. As such, the human capital of a service provider is the collective of individuals' knowledge and skills that resides on the HRM service provider unit level. Existing studies show that HRM service providers' human capital includes HRM professionals' knowledge of HR information technologies, HR processes, and communication which contribute positively to perceived HRM effectiveness for workers (Boselie \& Paauwe, 2005; Han, Chou, Chao, \& Wright, 2006) and worker satisfaction with HRM practices (Meijerink \& Bondarouk, 2013).

\subsubsection{Social capital of HRM service providers}

Although it has also been conceptualized as relational (e.g. trust, reciprocity) and structural (e.g. tie strength, structural holes) network characteristics, as a dimension of intellectual capital, social capital amounts to the knowledge that is mobilized through social relationships within an organization (Nahapiet \& Ghoshal, 1998). In an HRM environment, social capital refers to the knowledge that is shared among the HR professionals that work within the HRM service provider unit. Previous studies found that HRM service providers rely on the social capital that is developed among HR professionals to provide high-value HRM services, since it enables HRM professionals to solve complex problems or develop new services that better meet the needs of workers (Maatman et al., 2010; Meijerink \& Bondarouk, 2013).

\subsubsection{Organizational capital of HRM service providers}

Organizational capital represents the knowledge which is codified, embedded or stored in knowledge containers (Youndt et al., 2004). In other words, it is the knowledge contained in, for example, processes, information systems, databases and manuals. HRM service providers rely on organizational capital for offering HRM services to workers in the form of self-service technologies, online portals and HRM processes (Maatman et al., 2010; Meijerink \& Bondarouk, 2013).

Although being important for creating high-level value, research shows that service providers do not need to equally invest in all three intellectual capital dimensions. For example, Hansen, Nohria, and Tierney (1999) showed that knowledge codification does not improve service performance when service professionals develop shared knowledge models through sharing knowledge. Put differently, organizational and social capital likely act as substitutes for creating highlevel service value. At the same time, service employees need to have the required knowledge and skills to absorb the knowledge coming from others (Szulanski, 1996) or to operate processes (Meijerink \& Bondarouk, 2013). This implies that social and organizational capital synergize with human capital (Reed et al., 2006; Youndt et al., 2004). Given the substitutive and synergistic interrelationships among the intellectual capital dimensions, we will study the human, social and organizational capital of HRM service providers as separate, yet interdependent drivers of HRM service value.

\subsection{Consumer human capital of workers}

An additional driver of service value, besides the intellectual capital of the service provider, is the human capital of service recipients - in our case workers who receive HRM services - which represents the knowledge, skills and abilities that recipients draw on to utilize provided services. In an HRM environment, it involves the knowledge and skills that enable workers to interact and communicate with an HRM service provider for explaining their needs and solving problems, or operate online portals which nowadays offer online training courses or secondary benefits selection modules (Meijerink et al., 2016). An important feature of this conceptualization is that the consumer human capital of workers is conceptually different from the human capital concept as embedded in the provider intellectual capital construct. That is, the former represents the knowledge, skills and abilities of an individual service recipient (i.e. a worker who receives HRM services), whereas the latter describes the knowledge and skills of the HR professionals that work within the HRM service provider unit. Specifically, consumer human capital describes the knowledge resources possessed by the individual recipient of HRM services for co-producing and using provided services, whereas human capital - as a dimension of provider intellectual capital - resides with the provider of HRM services for providing selected services.

The consumer perspective considers consumer human capital to be important by arguing that service utilization by service recipients is what determines the value of services. The idea that recipients create value through service utilization follows from the notion that the needs of the recipient will not be met when recipients fail to utilize a service (Grönroos, 2011; Gummeson, 1998; Priem, 2007). Priem (2007: 222) notes that "fundamental to the consumer perspective are the ideas that value is experienced by consumers during their consumption activities". According to consumer perspective scholars (Grönroos, 2011; Gummeson, 1998; Priem, Li, \& Carr, 2012), this implies that service recipients are the ones who create and experience value, since they apply provided products and services to meet their needs. Provided that consumers create value, the consumer perspective predicts that "each consumer's human capital determines how much value he or she actually experiences" since it enables consumers to fit services to their needs through consumption (Priem, 2007: 224). Research shows that these consumer perspective principles also apply to HRM, by highlighting that the consumer human capital of workers relates positively to their perceptions of HRM service value (Meijerink et al., 2016).

\subsection{A configuration perspective on provider and consumer resources}

Despite the positive contributions of provider intellectual capital and of consumer human capital to value creation proposed here, empirical evidence has been mixed. Several studies have shown that provider intellectual capital is positively correlated with the service value experienced by recipients (Jiang, Chuang, \& Chiao, 2015; Liao, Toya, Lepak, \& Hong, 2009), whereas others have not found any significant 
effect of provider intellectual capital on service value (Boselie \& Paauwe, 2005; Meijerink et al., 2016). Similar inconsistencies consumer perspective research, with some studies showing that consumer human capital is significantly and positively correlated with value (McKee, Simmers, \& Licata, 2006; Van Beuningen, De Ruyter, Wetzels, \& Streukens, 2009), whereas others fail to find such effects (Auh, Bell, McLeod, \& Shih, 2007).

One could argue that these empirical inconsistencies are a consequence of irregularities in provider-consumer relationships. However, in our view, such an explanation is over simplistic. Instead, we argue that these inconsistencies follow from difficulties in conceptualizing and measuring the complex, non-linear and interdependent relationships between provider intellectual capital and the consumer human capital. A theoretical perspective that allows to synthesize the intellectual capital and consumer perspectives is configuration theory, which has three unique features that help explaining inconsistencies in correlation results (Fiss, 2011). First, configuration theory proposes causal asymmetry by distinguishing between the necessity and sufficiency of variables in explaining an outcome. Necessity means that an outcome can only be achieved if the causal condition is present (Fiss, 2007). In our study, this equates to high HRM service value for workers being realized if, and only if, high provider intellectual capital or high consumer capital of workers is present. However, a necessary condition might not be sufficient to produce the outcome if it depends on the presence of other conditions with which it forms a configuration (Fiss, 2011; Ragin, 2008). The intellectual capital and consumer perspectives are correlation-based theories which conceptualize provider intellectual capital and consumer human capital as conditions which are necessary and sufficient for creating high service value. This however produces inconsistent results in cases where these causal conditions are only necessary, but not sufficient. As such, as a first step in explaining observed inconsistencies, we apply configuration theory to explore whether the intellectual capital of HRM service providers and consumer human capital of workers are necessary conditions for high HRM service value.

Second, configuration theory argues that only bundles of causes (here, the human, social and/or organizational capital of providers and consumer human capital) are sufficient to produce an outcome of interest (i.e. high HRM service value) (Fiss, 2011; Ragin, 2008). Combining provider intellectual capital and consumer capital into configurations helps to further overcome inconsistencies in the predictions made by the intellectual capital and consumer perspectives. Namely, when intellectual capital researchers examine providers' utilization of resources, they neglect how those resources are utilized by service recipients. In particular, intellectual capital theory overlooks how consumer human capital can be a condition through which provider intellectual capital is effectively utilized during consumption. Conversely, the consumer perspective discusses strategies for growing and substituting consumer human capital (Priem, 2007) but remains silent on the intellectual capital resources that providers deploy in enacting such strategies. As such, we propose that both theoretical perspectives could be complementary in that the causal conditions proposed by one theory provide a boundary condition for the causal conditions proposed by the other on having an effect on service value. Therefore, as a second step, we explore whether configurations of the intellectual capital of HRM service providers and consumer human capital of workers are sufficient for high HRM service value.

Lastly, configuration theory proposes equifinality as a useful concept for explaining inconsistent relationships (Gresov \& Drazin, 1997). Equifinality refers to a situation where multiple configurations can be equally effective in realizing a desired state (i.e. create high HRM service value) (Fiss, 2007; Katz \& Kahn, 1978). This is likely the case since configuration components can substitute for each other such that organizations can be flexible in developing towards one of multiple configurations which are effective for creating value. Inconsistent results likely occur when research overlooks the equifinality principle since the absence of a value-creating configuration could nevertheless result into high HRM service value for workers when substituted for by another. Therefore, we examine whether multiple configurations of the intellectual capital of HRM service providers and consumer human capital of workers are equivalent in creating high HRM service value.

\subsection{Necessary conditions for high HRM service value}

As a first step in unraveling inconsistent relationships, we first conceptualize provider intellectual capital and consumer human capital as necessary conditions for high HRM service value. To explain why these causal conditions are necessary, we apply insights from service marketing research as these conceptually outline the roles of provider and recipients, and thus their resources, in value creation processes (Grönroos, 2011; Gummeson, 1998; Vargo \& Lusch, 2008). Specifically, on the basis of the marketing concept of value propositions, we expect the intellectual capital of HRM service providers and consumer human capital of workers to be substitutable necessary conditions. A basic premise of marketing research is that "the enterprise cannot deliver value, but only offer value propositions" (Vargo \& Lusch, 2008: 8). This premise holds that a service is not value-laden; meaning that service providers cannot add value to services or goods. Rather, the service recipient is considered to be the creator of value-in-use, because it is through consumption activities that recipients use a good or service to satisfy their own needs (Grönroos, 2011; Gummeson, 1998; Vargo \& Lusch, 2008). This implies that service providers cannot create value by themselves since it is up to service recipients how they utilize a service. Rather, service providers are viewed as providing the opportunity for recipients to create value-in-use by offering a service. Therefore, service marketing views the provision of a service by the provider as equating the provision of a value proposition, which is a promise of potential value (Ballantyne \& Varey, 2006) that is realized when recipients utilize the service provided to them (Priem, 2007).

Since provided services represent a value proposition, it is expected that high levels of intellectual capital of an HRM service provider is a necessary condition for high value. The human, social or organizational capital of an HRM service provider is necessary, while the provider needs them to produce a high-quality value proposition, such as advice (i.e. human capital), and self-service systems (i.e. organizational capital) that workers may appropriate in order to meet their needs through consumption. Workers will not be able to create value-in-use (Vargo \& Lusch, 2008) without a value proposition, implying that high value can only be created if the HRM service provider is able to develop such necessary value propositions. As such, the intellectual capital of the HRM service provider needs to be well developed and thus represent a necessary condition since, otherwise, value propositions are unlikely to be of high quality and thus not turned into value by workers.

However, workers may be able to substitute for the intellectual capital of HRM service providers in creating high-quality value propositions. Substitutive effects occur when causal conditions are replaced by an alternative (Delery, 1998). Collaboration between providers and recipients enable recipients to contribute to the creation of value propositions through their involvement in the delivery of services, that is in co-production (Grönroos, 2011; Vargo, Maglio, \& Akaka, 2008). The idea is that co-production allows providers and recipients to engage in a process of mutual adjustment where the service (i.e. value proposition) is reconsidered and modified to the satisfaction of both parties. Research shows that workers co-produce HRM services in various ways: when they join user boards (Bondarouk et al., 2009), update HR databases (Meijerink \& Bondarouk, 2013; Ruta, 2009a, b) and provide information that $\mathrm{HR}$ professionals use to address inquiries (Cooke, 2006). In fact, workers co-produce various HRM services, such as training and development, performance appraisal, participation and teamwork, by attending training sessions, discussing their past performance, seeking feedback, joining decision-making processes and collaborating with team members. Since workers are involved in co- 
producing HRM services, they can shape the value proposition and might be able to substitute for the lack of intellectual capital from the provider. Research into contemporary HRM functions show that it is quite possible that an HRM service provider lacks well-developed intellectual capital because constant changes make old routines and the experience of HR professionals obsolete (Cooke, 2006; Meijerink \& Bondarouk, 2013). Workers can replace this lack of welldeveloped intellectual capital through interacting with the HRM service provider. It has even been shown that consumers can initiate and take the lead in service processes. In an HRM environment, such recipientdriven processes do take place; for example, when workers proactively negotiate so-called idiosyncratic deals (Hornung, Rousseau, \& Glaser, 2008). During co-production activities, workers can leverage their knowledge and skills in implementing HRM to ensure that HRM services fit their needs and that a high-quality value proposition emerges for them. As such, the human capital of workers can substitute for absent provider intellectual capital during co-production, and become a necessary condition for high value in that the recipients leverages their consumer human capital to co-produce the value proposition. On this basis, we propose the following:

Proposition 1. High intellectual capital of the HRM service provider or high consumer human capital of workers, but not both, are necessary to create high HRM service value for workers.

\subsection{Equivalent configurations as sufficient conditions for high HRM service} value

By themselves, provider intellectual capital or consumer human capital are however unlikely to be sufficient for high service value, for example, because co-production requires interaction (Vargo \& Lusch, 2008) and because consumers likely need knowledge and skills in later phases when they turn a value proposition into value-in-use (Priem, 2007). Therefore, to further uncover the complex interrelations among provider and recipient resources, and in line with the provider and consumer roles discussed before, we expect equifinality (Katz \& Kahn, 1978) meaning that multiple configurations of provider and recipient resources are sufficient to create the same outcome - i.e. high HRM service value for workers. In other words, we test the proposition that different potential configurations can all result into high value for workers. The various configurations that produce high value are explained below and summarized in Fig. 1.

The two dimensions included in Fig. 1 follow from the intellectual capital and consumer perspectives to indicate that value-creating configurations are formed through the interdependencies among, respectively, the intellectual capital of HRM service providers and consumer human capital of workers. As noted before, intellectual capital is a multi-dimensional construct that consists of human, social and organizational capital which can synergize and/or substitute in value creation processes (Reed et al., 2006; Youndt et al., 2004). Therefore, to uncover the inner-workings of configurations of provider and recipients resources, we study how the human, social and/or organizational capital of HRM service providers and consumer human capital of workers interplay in creating high-level HRM services. For the sake of brevity, we will however refer to the set of human, social and/or organizational capital of the HRM service provider as 'intellectual capital'.

On this basis, and as shown in Fig. 1, one can distinguish four configurations, or four scenarios, that reflect how provider and recipient resources can interrelate. One of these configurations (i.e. Scenario 4) however represents a 'deadly combination' that offers no possibilities for creating high-level value. This is the configuration that includes both low provider intellectual capital and low consumer human capital and results into low HRM service value, because all necessary conditions (see our Proposition 1) for high service value are absent.

In line with the equifinality principle, the remaining three configurations are likely to be equivalent in explaining high HRM service value. As explained below, this is to be expected on the basis of service marketing insights which hold that service providers and recipients can adopt different roles in value creation processes and thus arrive at high value through alternative paths. Below we discuss three scenario's to motivate our proposition that multiple configurations of provider and consumer resources are sufficient to create high value.

\subsubsection{Scenario 1}

It is expected to observe a scenario/configuration in which HRM service provider and worker resources synergistically interrelate to create high value (see Scenario 1 in Fig. 1). Synergies occur when causal conditions work together such that the effect of one causal condition on value depends on the presence of others (Delery, 1998). Services are value propositions in the form of provider knowledge resources (Vargo \& Lusch, 2008), such as organizational capital (e.g. HR portals, HR processes) and human capital (e.g. information provided by HR professionals). Provided that value is created in use, a provider's intellectual capital will not yield value if service recipients are not able to use the knowledge provided. Thus, consistent with the consumer perspective, recipients must have well-developed human capital to use a service and create value out of the intellectual capital provided to

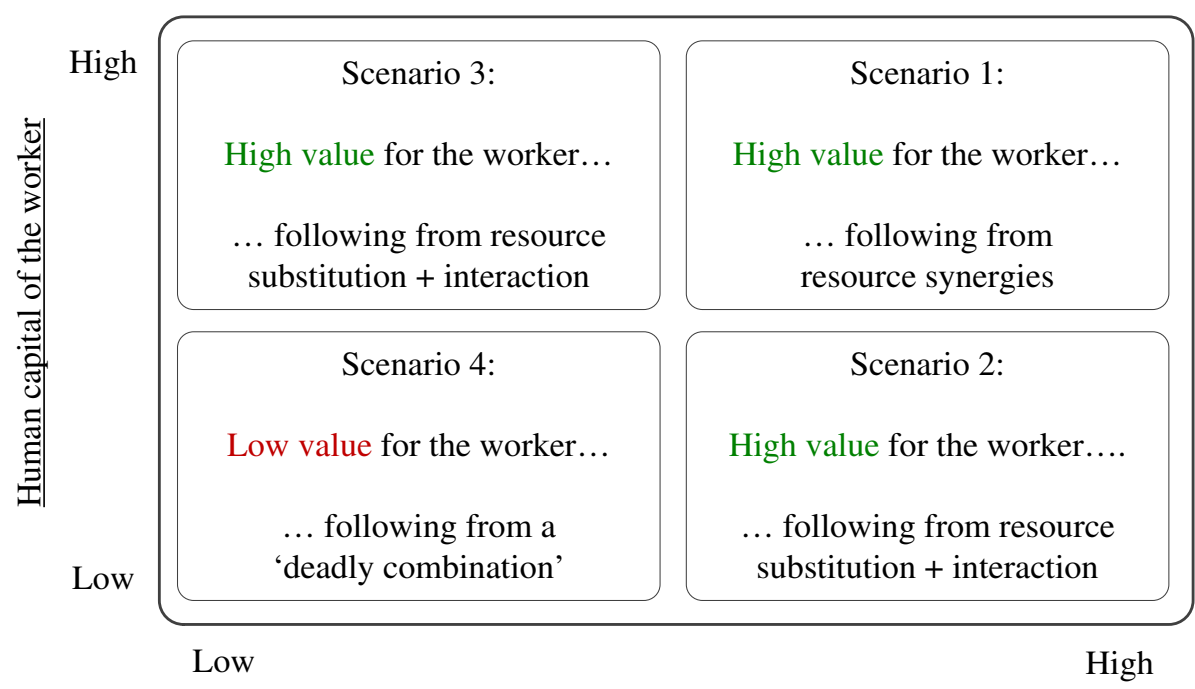

Fig. 1. Configurations of provider and worker resources that provide HRM service value for workers.

Intellectual capital of the HRM service provider 
them (Meijerink et al., 2016; Priem, 2007). This is in line with insights from knowledge management research which found that the extent to which knowledge coming from others (in our case: provider intellectual capital) is efficiently internalized and utilized depends on the recipient's (in our case: a worker) prior knowledge (Szulanski, 1996). Put differently, the intellectual capital of the HRM service provider increases worker's perceptions of the quality of HRM and reduces their nonmonetary costs - as the two dimensions of HRM service value - when workers possess the required consumer human capital. Therefore, one scenario where high HRM service value emerges is when high intellectual capital of the HRM service provider is combined with high consumer human capital of workers.

\subsubsection{Scenario 2}

Another scenario were high value emerges is one where the consumer human capital of workers is substituted for by the intellectual capital of the HRM service provider (see Scenario 2 in Fig. 1). This is likely because service providers can adopt a value co-creator role (Vargo et al., 2008) which allows them to compensate for inabilities on the side of the recipient. That is, service marketing researchers have noted that providers are not restricted to developing value propositions because they can join and support service recipients at the moment of value-in-use creation (Grönroos, 2011). Research shows that HRM service providers engage in co-creation by providing on-site assistance, call centre help or online advise to support workers on how to utilize HRM services (Cooke, 2006; Farndale et al., 2009). The provider can compensate for a potential lack of human capital on the worker side at the moment of co-creation by relying on its human capital by instructing the worker how to use HRM services and, thus, secure an effective value-in-use creation. Also, the organizational capital of the provider can replace worker human capital. For instance, Bondarouk et al. (2009) found that workers appreciate the accompanying, codified information on an online career mobility bank on how to find posted job openings. As such, the service provider can offer its organizational capital through co-creation activities to allow a user who lacks welldeveloped human capital to create high value-in-use. However, cocreation and, thus, knowledge substitution requires interaction between the provider and recipient because without it a recipient cannot access the specialized competences of the provider (Grönroos, 2011; Jaakkola \& Hakanen, 2013). This means that it is only when the HRM service provider is invited to support incapable workers that the human capital of workers can be substituted with high intellectual capital of the provider. In other words, users can successfully create value-in-use with having underdeveloped human capital themselves when they interact with an HRM service provider (Grönroos, 2011) because this interaction provides users access to knowledge and skills of the provider that helps them in co-creating value-in-use (Grönroos, 2011; Gummesson, 2008). Therefore, a second scenario that likely results in high HRM service value is one where low consumer human capital of a worker is combined with the presence of high intellectual capital of the HRM service provider and the interaction between the provider and worker.

\subsubsection{Scenario 3}

In the final scenario, consumer human capital can substitute for a lack of intellectual capital of the provider (see Scenario 3 in Fig. 1). This is likely because service recipients can adopt the role of a co-producer to align the value proposition to their needs (Vargo et al., 2008). Information technologies in contemporary HRM service delivery processes enable workers to co-produce value propositions and create organizational capital without having to interact with an HR professional. For example, Meijerink and Bondarouk (2013) and Ruta (2009a, b) find that workers, by using HR portals, remotely update data stored in the databases of HR service providers. This implies that they co-produce the resources used by the provider for generating value propositions. Furthermore, Schneider and Bowen (1995) discuss the 'substitute for leadership role' for service recipients. This means that recipients can take over some of the activities that, otherwise, would be performed by the service provider's management. Gouthier and Schmid (2003) go even further and reason that: "the customer might even determine tasks, competencies and responsibilities of the firm's encounter staff" when they encounter staff that are unable to do so (p. 125). This means that workers may compensate for the lack of human capital on the HRM service provider side through co-production when relying on their knowledge and skills. However, workers have to interact with HRM service providers to compensate for low human capital of HR professionals because, for co-production and, thus, knowledge substitution to occur, requires interaction (Vargo \& Lusch, 2008). Therefore, it is expected that high value for workers can also result from low provider intellectual capital, but only when combined into a configuration with high worker human capital and the presence of the interaction between the provider and recipient (i.e. Scenario 3 in Fig. 1).

In all, the three scenarios outlined above suggest that HRM service providers and workers can create value through different means. Specifically, they imply that high value can be created when provider and recipient resources synergize (Scenario 1 ) or substitute (Scenario 2 and 3). A condition for the latter to occur is however that the provider and recipient interact. On this basis, we propose the following proposition:

Proposition 2. Three configurations which include synergies or substitutions among (1) the human, social and/or organizational capital of the HRM service provider, (2) consumer human capital of workers and (3) presence of interaction are sufficient to create high HRM service value for workers.

\section{Methodology}

\subsection{Study design and participants}

Data obtained from a sample of workers and centralized HRM service providers from 19 Dutch organizations were used to examine our propositions. Centralized HRM service providers, which offer HRM services such as training and personnel administration, were selected as the focal HRM service provider for two reasons. First, centralized HRM service providers centralize resources, including HR professionals, information technologies and processes. Therefore, they can be considered an organization-within-an-organization. Previous studies have shown that centralized HRM service providers bundle human, social and organizational capital (Farndale et al., 2009; Meijerink \& Bondarouk, 2013). This means that all intellectual capital dimensions are present empirically in a centralized HRM service provider. Second, research shows that workers can obtain centralized HRM services through multiple delivery channels, such as online self-services and HR portals, but also directly by inquiring a call centre (Cooke, 2006; Farndale et al., 2009). Therefore, centralized HRM service providers form a useful empirical setting as their users differ in the degree of interactions they have with the HRM service provider.

To reduce the likelihood of common-rater effects, data were collected both from representatives of the HRM service providers and from their recipients (the workers). The sampling procedure consisted of two phases. First, personal invitations were sent to the HR directors of a total of 95 organizations. In total, 19 organizations agreed to participate, an inclusion rate of $20 \%$. The sample means of the 19 participating centralized HRM service providers were compared to those that decided not to participate to reduce concern over potential sampling bias. Results from $t$-tests and chi-square tests indicated that the participating service providers did not differ significantly from those that did not in terms of the number of years of operation $(t(42)=0.583$, $\mathrm{p}=0.56)$, number of workers served $(t(42)=1.11, \mathrm{p}=0.27)$, and industry $\left(\chi_{(1)}^{2}=3.04, p=0.08\right)$. Overall, $26 \%$ of the participating organizations came from the public sector and $74 \%$ were service firms. 
They all had centralized HRM service providers with between 5 and 250 HR professionals serving between 1300 and 130,000 workers.

A paper-and-pencil questionnaire was sent to each HRM service provider's management to obtain data on the intellectual capital of the HRM service provider. Whenever possible, to avoid single-respondent bias, all management team members (ranging from 1 to 6 across the organizations) received the questionnaire. In total, 65 questionnaires were sent out, and at least one completed questionnaire was returned from each HRM service provider. In total, 53 questionnaires were returned representing a response rate of $83 \%$.

During the second phase, 6595 workers from the 19 organizations were randomly selected. Non-managerial and managerial workers have different perceptions of HRM services (Liao et al., 2009). Therefore, stratified random sampling reflecting the workers' job description was applied (non-managerial workers ranged from $67 \%$ to $92 \%$ across the organizations). Workers received a questionnaire to measure their consumer human capital, perceptions of value and their interaction with the HRM service provider one month after the HRM service provider's managers administered theirs. Invitations were sent by email which included a link to the online questionnaire. The workers had four weeks to complete their questionnaires and received two reminders by email. All completed surveys were sent directly to the research team to assure workers of the confidentiality of their responses. A forced-entry technique was used to avoid missing values.

In total, 2002 workers who complemented the questionnaire were retained for the final analysis, equivalent to a $30 \%$ response rate. In all, $32.5 \%$ of the responding workers were female and $78.0 \%$ were nonmanagerial workers. Furthermore, the respondents were on average 46 $(\mathrm{SD}=10$; Skewness $=-0.37)$ years old and had worked for 17 $(S D=12$; Skewness $=0.44)$ years at their respective organization.

\subsection{Measurement of the main variables}

Unless stated otherwise, existing scales were used to measure the variables of interest, by relying on a Likert scale ranging from 1 (strongly disagree) to 5 (strongly agree). Two researchers, both proficient in Dutch and English, translated the established items from English into Dutch and back again to ensure the items were correctly represented. Appendix A provides an overview of the measurement scales used for the independent variables since these have been adapted to fit the HRM service provider context (see below).

\subsubsection{Human capital of the HRM service provider}

The 5-item scale of Youndt et al. (2004) was used to measure the human capital of the HRM service provider. This was adapted slightly to fit the HRM context (e.g. 'the employees of the HRM service provider are highly skilled'). This human capital scale has never been used in an HRM environment, so a confirmatory factor analysis was conducted to verify its consistency. In AMOS 19.0 a one-factor model of human capital on which the five items were assumed to load was estimated. This model had a good fit $\left(\chi_{(5)}^{2}=1.29 ; \quad \mathrm{NFI}=0.92 ; \quad \mathrm{CFI}=0.98\right.$; GFI $=0.96 ; \quad$ RMSEA $=0.07)$ as well as acceptable reliability $(\alpha=0.79)$. Since human capital represents a collective construct, the responses of the individual HRM service provider managers was aggregated to the HRM service provider level. In order to justify aggregation the within-group agreement or $\operatorname{rwg}(\mathrm{J})$ (James, Demaree, \& Wolf, 1984) and intra-class correlation (ICC[1]) were computed. The values of the two indices $(\operatorname{rwg}(\mathrm{J})=0.99$; ICC[1] $=0.58$ ) were above the cut-off points suggested in the literature (LeBreton \& Senter, 2008) and so justified data aggregation.

\subsubsection{Social capital of the HRM service provider}

Since social capital represents the knowledge that is mobilized through social relationships within the HRM service provider, we used three of the seven items used by Reed et al. (2006) to measure the social capital within the HRM service provider (e.g. 'The employees of the
HRM service provider mutually share relevant information about business units and end-users that the HRM service provider serves.'). The four other items used by Reed et al. (2006) were dropped since they measured human capital (e.g. "How adequately do your employees have the capacity to partner with customers?") or they did not fit the HRM context (e.g. "How adequately do your employees share information about competitors to other departments?"). Therefore, we added two items based on case study research into the intellectual capital of centralized HRM service providers (Meijerink \& Bondarouk, 2013). The one-factor social capital measurement model that included the five items had an acceptable fit $\left(\chi_{(4)}^{2}=1.21\right.$; NFI $=0.97$; $\mathrm{CFI}=0.99 ; \quad \mathrm{GFI}=0.97 ; \quad \mathrm{RMSEA}=0.06) \quad$ and reliability score $(\alpha=0.89)$. We are interested in knowledge exchange within the HRM service provider, so we aggregated the social capital scores to the HRM service provider level which was justified by the within-group agreement and intra-class correlation values: $\operatorname{rwg}(\mathrm{J})=0.98$; $\operatorname{ICC}[1]=0.45$.

\subsubsection{Organizational capital of the HRM service provider}

We utilized three items from Youndt et al. (2004) and three from by Reed et al. (2006) to measure the organizational capital of the HRM service provider as we had to eliminate some items from each scale which did not fit the HRM context (e.g. "Our organization uses patents and licenses as a way to store knowledge"). Examples of items that were use are: "Much of the knowledge in the HRM service provider is documented in manuals, process descriptions, (knowledge) databases and information technologies, etc." and "The HRM service provider embeds much of its knowledge in systems and processes". The factor analysis of a one-factor organizational capital measurement model that included the six items revealed a good fit $\left(\chi_{(9)}^{2}=0.85\right.$; NFI $=0.93$; CFI $=0.99 ; \quad$ GFI $=0.95 ; \quad$ RMSEA $=0.00)$ and reliability score $(\alpha=0.82)$. The within-group agreement and intra-class correlation values justified the aggregation of the managers' responses on organizational capital to the HRM service provider level: $\operatorname{rwg}(\mathrm{J})=0.98$; IC$\mathrm{C}[1]=0.55$.

We conceptualized human, social and organizational capital to reflect three separate dimensions of the intellectual capital of HRM service provider. To assess whether this is empirically the case, we ran an exploratory factor analysis in SPSS to explore whether the three intellectual capital dimensions are separate. Consistent with our conceptualization, the factor analysis produced three factors with an Eigenvalue greater than 1. Furthermore, the items loaded on the human, social and organizational capital factors as proposed (i.e. lowest loading was 0.66 ). High cross-loadings of items onto either of the two other intellectual capital dimensions were not found (i.e. the highest cross-loading was 0.39 ). Finally, we ran a confirmatory factor analysis in AMOS where we examined the fit of a correlated factors model in which the three intellectual capital dimensions are conceptually different but correlated. The results were consistent with the exploratory factor analysis in that this model fitted the data well $\left(\chi_{(86)}^{2}=1.09\right.$; $\mathrm{p}=0.25$; CFI $=0.97$; GFI $=0.82$; RMSEA $=0.04$ ). Therefore, we can be confident that the human, social and organizational capital constructs do jointly measure intellectual capital while being conceptually and empirically distinct.

\subsubsection{Consumer human capital of the worker}

To measure the consumer human capital of workers, we relied on the HRM-specific human capital scale of Meijerink et al. (2016) because it measures workers' knowledge and abilities to co-produce and consume HRM services (such as online worker self-service systems and call centre services). This construct consists of two first-order dimensions: HR functional human capital (i.e. knowledge and skills to utilize HR services: 'I know exactly where I can make requests regarding personnel administration') and interaction human capital (i.e. ability to interact and collaborate with HR professionals: 'I am always able to clearly explain my HR-related problems to an employee of the HRM service provider'). Together, these form the second-order construct consumer 
human capital of the worker. The factor analysis of this model showed a good consistency fit $\left(\chi_{(242)}^{2}=12.46 ; \quad \mathrm{NFI}=0.98 ; \quad\right.$ CFI $=0.98$; $\mathrm{GFI}=0.99$; RMSEA $=0.07)$, as well as reliability $(\alpha=0.85)$.

\subsubsection{Provider-worker interaction}

We relied on an index scale to assess the degree to which a worker interacts with the HRM service provider. This includes two items based on two types of HRM services that require a worker to interact directly within the HRM service provider. Previous studies show that these two HRM services include: inquiries to an HR professional to obtain support with using online self-services; and, obtaining information from an HR professional regarding HR policies and procedures (Cooke, 2006; Farndale et al., 2009). The presence of interaction with the HRM service provider was measured by asking respondents whether they had made use of these two HR services during the previous twelve months using a dichotomous yes/no scale.

\subsubsection{HRM service value for workers}

Value for workers refers to the surplus between quality and nonmonetary costs of HRM services as perceived by a worker. Given that value is the focal outcome variable in this study, we followed the advice of Blocker (2011) to measure it using a higher-order construct which is reflected by two lower-order latent constructs, namely: HR service quality; and, non-monetary costs of HR services. To measure the quality of HR services, we used the HR service quality scale developed by Biemans (1999) because it includes items that measure the quality of HRM service processes (e.g. 'Employees of the HR service provider are always courteous with me') as well as items measuring the quality of service outcomes (e.g. 'The HR service provider provides its services right the first time'). Meijerink et al. (2016) found that HR service quality is reflected by two constructs, namely: service outcome quality; and, service delivery process quality. These two dimensions were treated as first-order constructs that together reflect the second-order construct HR service quality. In measuring the costs of HR services, we used a scale developed by Meijerink et al. (2016) that measures their non-monetary costs in terms of the time, energy and effort spent by workers in co-producing and consuming HRM services. Examples of items that were used were: "Making requests concerning personnel and payroll services takes me a lot of time" and "Making enquiries to the HRM service provider costs me a lot of effort". This measure consists of two dimensions (costs of HR administrative services and costs of call centre services). Together, these reflect the second-order construct in the form of costs of HR services.

After creating the second-order constructs 'HR service quality' and 'costs of HR services' we used them to reflect the third-order construct 'value for workers'. The model that measured this proposed construct had an acceptable fit $\left(\chi_{(242)}^{2}=9.17 ; \quad \mathrm{NFI}=0.93 ; \quad \mathrm{CFI}=0.94\right.$; $\mathrm{GFI}=0.90 ;$ RMSEA $=0.06)$ and reliability $(\alpha=0.84)$.

\subsection{Analytical technique: fuzzy-set qualitative comparative analysis}

To uncover value creating configurations and their inner workings of HRM service provider intellectual capital and consumer human capital of workers, we relied on the fuzzy-set qualitative comparative analysis (fsQCA) technique. QCA is case-based and relies on set-theory logic. This means that it classifies cases (i.e. the workers) into sets, each representing a configuration that produces the outcome in question. More specifically, fsQCA helps to unravel causal complexity because it is based on the idea that cases belong to multiple sets that represent the causal conditions (e.g. workers with high human capital and workers that do not interact with HR professionals) and outcome of interest (i.e. workers who experience high value). As such, QCA uncovers whether cases that share the same outcome, also share membership of the multiple sets that each represent the causal conditions.

Furthermore, the specific features of fsQCA make it particularly suitable for examining this study's propositions. First, fsQCA helps in testing our first proposition on the necessity of causal conditions for high service value. It does this by distinguishing between the necessity and sufficiency of causal conditions. Necessity means that an outcome can only be attained if a condition, or combination of conditions, is present (Fiss, 2007). Thus, necessity exists when the outcome of interest is a subset of the set representing the desired causal condition. As such, fsQCA allows one to assess whether workers who experience high HRM service value are a subset of workers who are served by an HRM service provider with a well-developed intellectual capital dimensions or are a subset of workers with their own well-developed consumer human capital.

Second, fsQCA explores the way in which set memberships intersect and, as such, uncovers the inner workings of configurations, thereby providing information about which scenarios - as summarized in Fig. 1 - produce high-level HRM service value. We do acknowledge that conventional linear regression analysis also allow to examine the interrelations among our causal conditions through estimating interaction effects. However, these interaction effects are hard to interpret when more than three independent variables are entered in the analysis (Fiss, 2007). For this study, we examine how five causal conditions interact, which makes the interpretation of regression results almost impossible. QCA helps to remedy this challenge by identifying whether workers share membership of different sets of causal conditions, and so uncovers how various causal conditions combine to produce the outcome of interest. In particularly, fsQCA allows one to allocate cases to groups where the causal condition is present (e.g. high consumer human capital) or absent (e.g. low consumer human capital). As such, it is particularly suitable to examine whether causal conditions relate in a synergistic fashion (i.e. Scenario 1 in Fig. 1) or that they can substitute for causal conditions that are absent (i.e. Scenario 2 and 3 in Fig. 1).

Finally, our second and final proposition is based on the principle of equifinality which predicts that multiple configurations reflect a different, yet equally effective pathway towards high service value. Here, fsQCA proves to be a more effective alternative for conventional regression analysis. Namely, although allowing for estimating interaction effects, regression analysis assumes that causal relationships are relevant for all cases under examination, which contrasts with the equifinality principle that different pathways lead to a similar outcome (Fiss, 2007; Gresov \& Drazin, 1997). QCA is able to identify multiple paths that lead to the same outcome of interest, because it relies on truth tables that represent all the theoretically possible combinations of the causal conditions. Each combination is a configuration that represents a potential path to high value. QCA empirically analyses which of these possible paths produce the outcome of interest and, thus, allows us to test our Proposition 2 on the multiple ways in which the resources of the HRM service provider and the workers jointly deliver high value.

\subsection{Fuzzy set calibration}

Workers are assigned degrees of membership in sets in fsQCA that represent the outcome and casual conditions through a process called calibration. Calibration transforms variables into a degree of set membership based on three thresholds: full membership (degree of set membership =1); full non-membership (degree of set membership $=0$ ); and, the cross-over point, which represents the point of maximum ambiguity as to whether a worker is more in or out of a set (degree of set membership $=0.5$ ). These thresholds have to be determined by the researcher, so we followed the advice of Ragin (2008) to rely on both empirical and theoretical arguments to avoid researcher subjectivity in setting thresholds. Appendix B shows the thresholds for the variables included in this study and the rationale behind them. Following others (Fiss, 2011; Ragin, 2008), we computed percentiles so that the upper 25 percentiles serve as the threshold for full membership; the lower 25 percentiles for full non-membership; and, the 50 percentiles represent the cross-over point. We combined this empirical 
evidence with theoretical knowledge from the HRM competencies, service marketing and intellectual capital literature to justify the calibration thresholds.

\subsection{Analysis procedure}

We relied on fsQCA 2.5 software (Ragin, 2008) to uncover the configurations that produce high-level HRM service using a two-step procedure: uncovering necessary conditions; and uncovering sufficient conditions.

\subsubsection{Uncovering necessary causal conditions (Step 1)}

Analysis of necessary conditions was conducted to test Proposition 1. The main outcome we are interested in is the set of workers who reported high HRM service value. A condition or set of conditions is necessary for this outcome to occur when high value can only be produced when this condition is present (Fiss, 2007). The formula which we used to assess the necessity of conditions for value is: Consistency $\left(\mathrm{Y}_{\mathrm{i}} \leq \mathrm{X}_{\mathrm{i}}\right)=\Sigma\left[\min \left(\mathrm{X}_{\mathrm{i}}, \mathrm{Y}_{\mathrm{i}}\right)\right] / \Sigma\left(\mathrm{Y}_{\mathrm{i}}\right)$, with $\mathrm{X}_{\mathrm{i}}$ representing the degree of membership in the selected causal conditions and $Y_{i}$ representing the degree of membership in the set of high value. This formula shows that a condition is necessary when the membership in the outcome is consistently less than the degree of membership in the causal condition. fsQCA offers the measures of consistency and coverage (Ragin, 2008) as test statistics that aid the interpretation of the results.

Consistency measures the degree to which cases sharing a given (combination of) condition(s) (e.g. high intellectual capital) agree in displaying the outcome of interest (i.e. high value). Correlation scholars would refer to consistency as the significance of a correlation coefficient. Consistency values have to be close to 1 which indicates that all cases sharing a causal condition also share the outcome. We followed the recommendations of Ragin (2008) and used a threshold value of 0.80 for the consistency of necessary conditions.

Adequate consistency is a precondition for evaluating set-theoretic coverage and measures the degree to which causal combinations account for instances of an outcome on a scale from 0 to 1 (Ragin, 2008). Given that multiple paths may result into high value, the coverage of each path gauges its empirical relevance which, in correlation analysis, would be indicated by the correlation coefficients or $\beta$-values. Hence, high coverage values indicate high empirical importance of a single causal condition or combinations thereof.

\subsubsection{Uncovering sufficient causal conditions (Step 2)}

To assess the sufficiency of causal combinations and thus test our Proposition 2, which indicates that a combination of causal conditions is a sub-set of the outcome in question, fsQCA starts with constructing a truth table. The truth Table $1 \mathrm{~s}$ a data matrix consisting of $2^{k}$ rows, where $k$ indicates the number of causal conditions used in the analysis. We include five causal conditions. Therefore, our truth table consists of

Table 1

Consistency and coverage scores of necessary conditions for high HRM service value. ${ }^{\text {a }}$

\begin{tabular}{lll}
\hline Causal condition(s) & Consistency & Coverage \\
\hline Individual effects & & \\
HC of the HRM service provider & 0.58 & 0.84 \\
SC of the HRM service provider & 0.61 & 0.86 \\
OC of the HRM service provider & 0.52 & 0.86 \\
HC of the worker & 0.63 & 0.82 \\
Provider-worker interaction & 0.43 & 0.83 \\
Substitution effects provider-worker resources & & \\
HC of the worker + HC of the HRM service provider & $\mathbf{0 . 8 1}$ & $\mathbf{0 . 8 3}$ \\
HC of the worker + SC of the HRM service provider & $\mathbf{0 . 8 3}$ & $\mathbf{0 . 8 3}$ \\
HC of the worker + OC of the HRM service provider & $\mathbf{0 . 8 0}$ & $\mathbf{0 . 8 3}$ \\
\hline
\end{tabular}

${ }^{\mathrm{a}} \mathrm{HC}=$ human capital, SC = social capital, OC = organizational capital. $\mathrm{N}=19 \mathrm{HRM}$ service providers, $\mathrm{n}=2002$ workers.
$2^{5}$ (=32) rows that represent all the theoretically possible configurations. FsQCA then sorts all 2002 empirical cases (i.e. workers) into each of these rows based on their degree of membership of all the causal conditions. As such, some truth table rows may contain many cases and others just a few or even none.

After this procedure, the researcher reduces the number of rows according to two conditions: a row must (1) contain at least a minimum number of cases, this value was set at 11 following the recommendation of Ragin (2008); and (2) achieve a minimum consistency level of 0.80 . Overall, 23 potential configurations/rows exceeded these conditions, and these included a total of 1405 workers which reported high HRM services.

Finally, an algorithm based on Boolean algebra is used to logically reduce the truth table rows to simplified configurations of causal conditions that are sufficient to yield high HRM service value.

\section{Results}

\subsection{Testing Proposition 1: necessary conditions for high HRM service value}

Proposition 1 predicts that high intellectual capital of the HRM service provider or high consumer human capital are substitutable necessary condition for high value for workers. To test this proposition, we examined whether high human, organizational or social capital of the provider and high consumer human capital separately are a necessary condition for high HRM service value (see Step 1 of the analysis procedure). As can be seen in Table 1, none of the individual causal conditions are by themselves necessary for high value (i.e. no single condition exceeds the 0.80 threshold for consistency). This implies that none of the provider or worker resources are always needed to yield high value for workers and is a first indication that provider and consumer resources might substitute as necessary conditions.

To perform the "substitutable necessary conditions" test, QCA examines whether two or more causal conditions joined by a logical "OR" (denoted by a "+" in Table 1) are necessary for high value. As can be seen in Table 1, high consumer human capital of workers or each of the three intellectual capital resources of the HRM service provider (consistency $=0.81,0.83$, and 0.80 for human, social and organizational capital respectively) are substitutable necessary conditions for high value. This implies that high value for workers occurs only when either the worker relies on high human capital or when the HRM service provider has high human capital or high social capital or high organizational capital. In other words, it is necessary that either one of both parties, but not both, brings a well-developed resource to value creation processes as, otherwise, no high value will be created. Therefore, we can accept Proposition 1.

\subsection{Testing Proposition 2: equivalent configurations for high HRM service value}

Proposition 2 predicts that multiple configurations (i.e. equifinality) involving synergistic and substitutive relationships among the human, social and organizational capital of HRM service providers, the consumer human capital of workers, and their interaction, are equally effective/sufficient for producing high HRM service value for workers. Table 2 shows the results of the sufficiency analysis showing which configurations are sufficient for high HRM service value to occur.

The cases which represent the overall set of configurations presented in Table 2 highly agree in displaying the outcome of interest (i.e. overall consistency $=0.86$ ) and $86 \%$ of them are instances of workers who experience high value (i.e. overall coverage $=0.86$ ). In fact, we find seven causal combinations that yield high HRM service value for workers. This validates the equifinality principle that multiple configurations are equally effective in producing a desired outcome.

Proposition 2 is founded on the idea that equifinality in configurations occurs because provider and recipient resources create high-level 
Table 2

Sufficiency analysis results: configurations for creating high HRM service value. ${ }^{a}$

\begin{tabular}{|c|c|c|c|c|c|c|c|}
\hline \multirow[t]{2}{*}{ Causal conditions } & \multicolumn{3}{|l|}{ Set 1} & \multicolumn{4}{|l|}{ Set 2} \\
\hline & $1 \mathrm{a}$ & $1 b$ & $1 \mathrm{c}$ & $2 a$ & $2 \mathrm{~b}$ & $2 \mathrm{c}$ & $2 \mathrm{~d}$ \\
\hline $\begin{array}{l}\text { High human capital of the HRM } \\
\text { service provider }\end{array}$ & $\bullet$ & $\theta$ & & & $\theta$ & & \\
\hline $\begin{array}{l}\text { High social capital of the HRM } \\
\text { service provider }\end{array}$ & $\bullet$ & $\theta$ & $\bullet$ & & & $\bullet$ & \\
\hline $\begin{array}{l}\text { High organizational capital of the } \\
\text { HRM service provider }\end{array}$ & & $\bullet$ & $\theta$ & $\theta$ & & & $\theta$ \\
\hline High human capital of the worker & & & & $\bullet$ & - & $\bullet$ & \\
\hline Provider-worker interaction & & & & & $\bullet$ & - & $\Theta$ \\
\hline Consistency & 0.87 & 0.93 & 0.92 & 0.87 & 0.90 & 0.87 & 0.87 \\
\hline Raw coverage & 0.46 & 0.16 & 0.28 & 0.37 & 0.15 & 0.25 & 0.38 \\
\hline Unique coverage & 0.12 & 0.02 & 0.01 & 0.00 & 0.00 & 0.00 & 0.08 \\
\hline Overall consistency & 0.86 & & & & & & \\
\hline Overall coverage & 0.86 & & & & & & \\
\hline
\end{tabular}

a Black circles ("๑") indicate the presence of a condition, whereas barred circles (" $\Theta$ ") indicate its absence. Blank spaces indicate that the presence of the selected condition is irrelevant, that is, high value can occur whether the condition is absent or present. $\mathrm{N}=19$ HRM service providers, $\mathrm{n}=2002$ workers.

value through two alternative paths; via resource synergies (Scenario 1 in Fig. 1) or resource substitution (Scenario 2 and 3 in Fig. 1). Therefore, to understand whether the observed equifinality in configurations manifests as a result of these two pathways and thus to test our Proposition 2, we turn to Table 2 to look into the inner workings of each of the seven configurations that produce high-level value.

As can be seen in Table 2, the seven configurations can be conceptually categorized into two sets. Namely, Configuration Set 1 yields high value irrespectively of whether high worker human capital or interaction is present/absent. This set consists of three different configurations $(1 \mathrm{a}-1 \mathrm{c})$ where only the presence/absence of HRM service provider resources matter for creating high value. As such, although these three empirically-derived configurations show that equifinality does occur, they fail to support the idea that this follows from synergistic or substitutional interrelations among provider and recipient resources. Configuration Set 2 does however provide support for this idea, because the configurations included in this set show that HRM service provider resources matter in combination with worker human capital and/or interaction for producing high value. Below, we discuss each of the seven configurations in greater detail.

\subsubsection{Configuration Set 1: provider-driven value creation}

Consistent with the necessity analysis, Configurations 1a to $1 \mathrm{c}$ show that at least one well-developed HR service provider resource has to be present to yield high HRM service value. Furthermore, they indicate the substitutive and synergistic relations among dimensions of provider intellectual capital. Configuration 1a shows that high human capital and high social capital of the HRM service provider are jointly sufficient for creating high value. In other words, both provider resources are synergistically interdependent, such that well-developed knowledge and skills of HR professionals creates high value for workers only when being shared within the HRM service provider.

Configuration $1 \mathrm{~b}$ indicates that intensive codification of knowledge in containers, such as manuals, processes and information technologies by the HR service provider, substitutes for a lack of HR professionals' skills and knowledge exchange. In other words, high HRM service value for workers is still created when the provider lacks high human and social capital (i.e. when Configuration 1a is absent), but only when the HRM service provider invested well in its organizational capital.

Configuration 1c indicates that, given the lack of well-developed organizational capital within the HRM service provider, intensive knowledge exchange among its HR professionals is sufficient for high value. In other words, to create high value, HR service providers rely on high social capital as a substitute for the lack of high organizational capital. Therefore, high value for workers is still created when the provider lacks high organizational capital, but only when HR professionals intensively share knowledge among each other.

\subsubsection{Configuration Set 2: recipient-driven value creation.}

Consistent with the necessity analysis, Configurations 2a to 2c show that high worker human capital has to be present to yield high value. Furthermore, they indicate that high value follows from substitutive or synergistic relations among provider and recipient resources. Configuration 2a indicates the sufficiency of the presence of high consumer human capital of workers in combination with the absence of high organizational capital of the HRM service provider. This shows that a workers' knowledge and skills substitutes for the lack of a proper HR portal, knowledge/data documentation or information technologies provided by the HRM service provider. As such, Configuration 2a provides empirical support the presence of our Scenario 3 (see Fig. 1) which builds on the idea that workers, through co-producing HRM services, can substitute for provider inabilities.

Configuration $2 \mathrm{~b}$ shows that a lack of high human capital of the provider, in combination with the presence of both high consumer human capital of workers and provider-worker interaction, is sufficient for creating high value. In other words, high value for workers still emerges when the HRM service provider has invested little in the knowledge and skills of its HR professionals, but only when users interact with the HRM service provider and have well-developed knowledge, skills and abilities themselves. As such, Configuration $2 \mathrm{~b}$ provides empirical support the presence of our Scenario 3 (see Fig. 1) which predicts that workers with well-developed human capital substitute for the absence of high human capital of the HR service provider when interacting with the HR service provider.

Configuration $2 \mathrm{c}$ indicates that high value results from the combination of high human capital of the worker, high social capital of the HRM service provider and high interaction between the provider and worker. In other words, high value emerges when a competent worker interacts with an HRM service provider where HR professionals intensively share knowledge within the HRM service provider. As such, this configuration lends support for our Scenario 1 (see Fig. 1) which builds on the value co-creation idea where the interaction between both parties enables them to tie together high-quality resources for cocreating value.

Configuration 2d indicates that the absence of interaction between the provider and worker in combination with the absence of high organizational capital of the provider is sufficient for creating high value. This shows that workers who do not interact with an HR service providers that invest little in codifying in information or relies on poor information technologies, experience high value. In other words, for experiencing high value, workers substitute for a lack of organizational capital on the HR service provider's side by avoiding interactions with the provider.

Concluding, among HRM service provider and worker resources, we find both synergistic effects (Configuration 2c) and substitutive effects (Configuration 2a and 2b). These results do confirm the presence of equifinality in value-creating configurations. However, we can only partially accept Proposition 2 since we only find empirical support for the fact that high value occurs in two scenarios - i.e. Scenario 1 (i.e. value follows from synergies among provider and recipient resources) and Scenario 3 (i.e. value follows from recipient resources that substitute for provider resources) - while Scenario 2 (i.e. value follows from provider resources that substitute for recipient resources) was not empirically observed.

\section{Discussion}

Given its importance for sustaining organizational success, researchers have studied the creation of value for service recipients - i.e. workers - who are internal to the firm. In doing so, they have relied 
either on the intellectual capital perspective to study the human, social and organizational capital of providers as antecedents to service value, or on the consumer perspective that considers the human capital of service recipients to be key for value creation. However, both perspectives are associated with inconsistent predictions and empirical results, and we argued that this might be resolved by applying them jointly using a configuration-theoretical perspective. Therefore, we examined how the knowledge resources of HRM service providers and of workers are configured to produce high HRM service value in order to better understand how the two perspectives are complementary in explaining HRM service value. Below we explain the theoretical and practical implications of our results.

\subsection{Theoretical implications}

A key finding of our study is that high value can only be realized if, and only if, the service provider OR the service recipient relies on a well-developed knowledge resource (e.g. high human capital). This has important implications for the intellectual capital and consumer perspectives. Namely, both perspectives assume that provider and recipient resources are necessary and sufficient conditions for high value to occur (Priem, 2007; Reed et al., 2006; Youndt et al., 2004). Previous studies already suggest that both conditions are at best necessary yet insufficient conditions for high service value while they find that provider and recipient resources do not correlate with (HRM) service value (Auh et al., 2007; Boselie \& Paauwe, 2005; Meijerink et al., 2016). Our results add to these insights by showing that neither one of the intellectual capital dimensions of the HRM service provider, nor the consumer human capital of workers, by themselves are necessary for high service value. Instead, we find that service provider and recipient knowledge resources substitute one another as necessary conditions, such that only one party needs to rely on a well-developed knowledge resources, and not both, or otherwise no value will be created. This implies that future HRM studies should not only differentiate between the necessity and sufficiency of HRM service provider and worker resources, but apply the consumer and intellectual capital perspectives in integration if they wish to assess which of these causal conditions are necessary for high HRM service value.

Second, our results imply that both perspectives only need to be integrated under particular circumstances for uncovering configurations that are sufficient for creating high service value. Namely, three out of the seven high-value configurations (i.e. Configuration Set 1) consist only of well-developed resources from the provider. This goes against our initial claim that only configurations that consists of both provider and recipient resources are sufficient to create high-level service value. A reason for this finding likely lies in the fact that we examined the value of transactional HRM services. Previous studies have shown that these services are routine in nature, and of limited complexity (Farndale et al., 2009; Meijerink \& Bondarouk, 2013). Accordingly, it is likely that workers do not need high-level knowledge and skills (i.e. consumer human capital) to utilize them. Further, HRM service providers can easily standardize transactional HRM services to meet the needs of many workers (Hofman \& Meijerink, 2015) by making investments in their organizational capital or to build strong social capital (Hansen et al., 1999; Ruta, 2009a, b). As such, when it comes to explaining the value of standardized services, there is no need to integrate the two theoretical perspectives since intellectual capital theory suffices. However, in explaining the value of customized or nonroutine services, the intellectual capital theory and the consumer perspective do appear to be complementary by predicting that provider and recipient resources combine synergistically while both parties need well-developed knowledge and skills to produce and consume such services. As such, we hope that our results motivate future studies to test this proposition and uncover additional conditions against which both theories require to be integrated for explaining high service value.

Third, although synergistic effects between provider and recipient resources are unlikely (and unnecessary) in standardized service settings, substituting effects do occur. Namely, our results show that a lack of high human or organizational capital of the HRM service provider still can result in high value of transactional HRM services, but only when the consumer possesses high levels of human capital (see Configurations 2a-2b). This implies that service recipients can have, what we call, a 'substitute for competence role', when they rely on welldeveloped consumer human capital to compensate for provider inabilities. A possible explanation of this substitutive effect lies in the value-in-use creation by service recipients with skillful recipients being able to create value out of sub-standard value propositions during service consumption (Grönroos, 2011; Priem, 2007). This implies that workers can actively influence HRM outcomes through other means than those described in the literature. Namely, previous studies showed that employees can be active players who influence HRM outcomes by negotiating idiosyncratic deals or crafting their jobs (Hornung et al., 2008). The shared idea behind these concepts is that employee try to realize desired outcomes before the delivery of HRM practices by requesting the provision of a unique HRM practices (i.e. idiosyncratic deals) or actively search for it themselves (i.e. job crafting). Our results imply that employee can affect HRM outcomes after the delivery of HRM practices when they rely on their consumer human capital to create value-in-use out of provided HRM practices. As such, future research could explore whether HRM outcomes are also dependent these post-delivery acts when employees effectively adopt a 'substitute for competence' role.

Fourth, our results show that adopting a 'substitute for competence role' may require the presence of an interaction between provider and users (Configuration 2b). This is notable because others have suggested that such interactions are necessary for the provider to compensate for users' inabilities (Fryberg \& Jüriado, 2009; Grönroos, 2011). Our research implies that such interactions are not needed for a provider to co-create high value, but rather that they enable the user to compensate for the inabilities of the provider. As such, in routine service environments, the intellectual capital and consumer perspectives are complementary, but in a substitutive manner in that low provider intellectual capital is an 'enabler' for high consumer human capital to substitute for underdeveloped provider resources in creating high service value.

Finally, our results provide support for the equifinality principle that multiple pathways can be equally effective in producing a desired outcome (Gresov \& Drazin, 1997). In fact, our results add to HRM configurations research while they suggest that one needs to distinguish between two levels of equifinality (Fiss, 2011). Namely, we find seven value-creating configurations which can conceptually be grouped into two sets: one that is provider-driven as it only includes resources of the HRM service provider (i.e. Configuration Set 1) and one that is recipient-driven while it mainly consists of high consumer human capital of workers that substitute for provider inabilities (i.e. Configuration Set 2). This implies that we can distinguish first-order equifinality (i.e. the seven individual configurations that produce high value) and secondorder equifinality (i.e. the two sets of configurations into which the seven configurations can be grouped). Although we find first- and second-order equifinality in the resources needed to implement HRM activities, the same likely applies to those very HRM activities. For instance, researchers have noted that different HRM systems such as high-performance, high-commitment and high-involvement work systems can be equally effective in stimulating employee performance (Lepak, Liao, Chung, \& Harden, 2006). These HRM systems would represent second-order equivalent configurations while they can be broken down into first-order equivalent configurations as HRM systems are configured using HRM practices that substitute one another and therefore, represent different configurations of different HRM practices that are equally effective in ensuring employee performance (Jiang, Lepak, Hu, \& Baer, 2012). As such, we hope that this study motivates future studies to further uncover the first- and second-order equifinality 
of HRM systems.

\subsection{Practical implications}

This study has several practical implications for both HRM service providers, as well as their beneficiaries; the workers. Firstly, we find that HRM providers can create high value for workers by investing in three different types of intellectual capital configurations. However, they do not have to invest intensively in all three intellectual capital components. Instead, relying on high human and high social capital is sufficient for creating high value. When absent, HRM service providers can compensate for a lack of human and social capital by developing high organizational capital. Finally, a lack of high organizational capital can be substituted for sufficiently by high social capital. Therefore, in aiming to increase value, HRM service providers should not simply invest on the basis of a more-is-better approach as advocated in previous studies occur (Priem, 2007; Reed et al., 2006; Youndt et al., 2004). Rather, the first three configurations that include only provider resources represent three strategies where, in some cases, HRM service providers can better divest themselves of some intellectual capital resources when investing heavily in others.

Relatedly, workers do not necessarily need high consumer human capital to experience high value. When the HRM service provider relies on one of the three intellectual capital configurations just described, high value will be created, irrespective of the worker's human capital. Therefore, decision-makers do not have to address workers' consumer human capital when relying on the provider's well-developed intellectual capital. However, a high level of worker human capital becomes detrimental when the provider lacks high organizational capital or high human capital. Essentially, we found that producing high value requires combinations of either (1) low provider organizational capital and high worker human capital, or (2) low provider human capital with high worker human capital plus interaction between them. As such, workers can compensate for providers' inabilities through their own high human capital themselves and/or by interacting with the HRM service provider.

Lastly, our results imply that HRM service providers that offer centralized transactional HRM services could, under certain conditions, pursue a strategy that is oriented at divesting or underinvesting in the knowledge and skills that they currently develop, share and/or codify. Given that many centralized HRM services providers are established to cut costs (Farndale et al., 2009; Meijerink et al., 2016), our results imply that such cost-oriented HRM services could reduce their intellectual capital investment and still provide a high-value service. This is provided that their users and clients (the organization's other business units) are willing to invest in the knowledge and skills of the workers that make use of transactional HRM services. In fact, HRM service providers that wish to disinvest in their intellectual capital can best disinvest in their organizational capital - in combination with investments in consumer human capital - since this is empirically highly relevant as indicated by the relatively high levels of coverage of the corresponding configuration.

\subsection{Limitations and future research}

The contributions of this research have to be seen in the light of its limitations. First, this study measured the value of services provides by centralized HRM service providers. Therefore, the results may not generalise well to other types of services. In particular, this study examined the value of operational HRM services, since most centralized HRM service providers are mainly involved in transactional processes and offering traditional HRM services such as staffing and training (Farndale et al., 2009). Operational HRM services are less complex than other services and therefore not require elaborate consumer human capital of workers. This could explain also why only well-developed provider competences are sufficient to produce high value (see
Configurations 1a-c). Therefore, future studies could focus on the complexity of services as a contingent condition that affects how provider and consumer resources configure to cause high value.

Second, although QCA is a particularly appropriate methodology for uncovering causal complexity, it has some drawbacks, since measurement calibration may invoke bias due to researcher subjectivity. However, the use of both empirical and theoretical knowledge coming from different data sources and different knowledge domains for determining calibration thresholds instils confidence that the results are robust enough in order not to be significantly biased by subjectivity. Nevertheless, the data about the intellectual capital of providers came from a small sample of HRM service providers. Although QCA is suited for analysing small-n samples (Ragin, 2008), the number of available cases may be restricted in the light of the number of theoretical possible resource configurations in the truth table. This implies that some potential configurations have not been empirically observed. Despite this, we found a variety of different provider and user resource configurations. This suggests that many potential configurations exist empirically. Nevertheless, we encourage future research to obtain data from a larger sample of providers in order to explore additional configurations that might exist empirically, but which were not found in our study.

Third, although intellectual capital theorists have stressed that knowledge equates intellectual capital once it is put to use, we did not examine the degree to which service providers utilize their knowledge and skills in examining the effect of intellectual capital on service value. At the same time, theoretically, knowledge utilization can be assumed given our results that provider resources (1) are interdependent and (2) dependent on consumer resources to influence value, which implies that individual provider resources are leveraged with the support of other resources (e.g. human capital that helps to put social capital to use in creating high-level service value). Nevertheless, future studies could study the degree to which knowledge resources are actually utilized in order to provide a more rigorous test of our hypotheses.

Lastly, although we introduced a time lag of a month between the measurement of the provider resources and value for workers, the data should be considered cross-sectional. Some have suggested that evaluation measures, like service value, measure an attitude that reflects a long-term evaluation (Cronin \& Taylor, 1992). Therefore, it could be possible that worker perceptions of value are not based on how well the provider's intellectual capital was developed at the time of measurement, but by its status prior to its measurement. Consequently, a limitation of this research is that it cannot determine fully whether the intellectual capital of HRM service providers affects value for workers causally. Therefore, future research could benefit from introducing longer time intervals between measuring value and its antecedents.

\section{Conclusion}

Despite the limitations raised, this study showed how the resources of providers and consumers integrate to better understand how the intellectual capital and consumer perspectives jointly explain high value. In particular, it confirms that both perspectives are needed to identify the necessary conditions for high service value and shows that service recipients/workers can compensate for the inability of providers to create high value. The fsQCA methodology further allowed us to uncover first- and second-order equifinality in value-creating resource configurations to which HRM services providers and/or workers contribute to. We hope that this study paves the way for more research that examines how configurations of providers' and recipients' resources integrate and/or uses fsQCA for explaining variance in perceived value by service recipients.

Jeroen Meijerink is an assistant professor of Human Resource Management at the University of Twente. His research focuses on HRM and Service Management in the Digital Economy and includes projects into HRM and technology-mediated services, value co-creation, HRM shared services and the relationship between HRM and (internal) 
customer experiences. His research is multi-disciplinary in nature and draws on concepts from intellectual capital theory, the consumer perspective and the service-dominant logic. His research has been published in peer-reviewed international outlets such as the International Journal of Human Resource Management, Human Resource Management, Personnel Review, European Journal of International Management, and The Services Industries Journal. So far, he has organized four international workshops and symposia that brought together researchers and practitioners with an interest in shared services and HRM co-creation. For this research, he collaborated with private and public organizations such as Ahold, the Dutch Railways (NS), KLM, the Dutch Ministry of the Interior, Pfizer, Stork, Tata Steel, Thales, TNT, and T-Mobile. For realizing his research initiatives, he was granted financial support from the Fulbright Scholar Program and the NWO.

Tanya Bondarouk is recognized as one of the founders of the new research area of Human Resource Management (HRM) and Technology, named electronic HRM. Her main publications cover an integration of Human Resource Management and social aspects of (Information) Technology Implementations, where she conducts interdisciplinary projects. Her works appear in peer-reviewed journals across the disciplines IT, HRM and general management, including European Journal of Information Systems, Journal of Information Systems, International Journal of HRM, and Personnel Review. She has conducted research with and provided advice to both private and public sectors including
Dutch and Belgian Ministries, Shell, Dow Chemical, KPN and Belgacom, Philips, KLM Air France, ABN AMRO Bank, Ford, IBM, and several healthcare organizations. She has been working as the Associate Editor of Personnel Review, the International Journal of Human Resource Management, and Book Series Editor of Advanced Series of Management (Emerald Publishers BV).

Her research performance is summarized as (co-)authoring more than 80 international journals and book chapters publications (since 2004), and 8 scholarly books; editing special issues into different aspects of HRM innovations in international refereed journals; initiating and organizing the Biennial e-HRM International conferences (since 2006).

\section{Acknowledgements}

We thank Dr. Marco Maatman for his assistance in the data collection. Furthermore, we thank Prof. Dr. Anne Keegan, Prof. Dr. Jaap Paauwe, Dr. Wing Lam and the two anonymous reviewers for their constructive feedback on previous versions of our manuscript.

\section{Funding}

This work was financially supported by the Dutch Ministry of the Interior and Kingdom Relations.

\section{Appendix A. Measurement scales used}

\section{Human capital of the HRM service provider}

- The employees of the $<$ HR SSC $>$ are highly skilled.

- The employees of the $<$ HR SSC $>$ can be considered the best in comparison to the employees of other HR SSCs.

- The employees of the $<$ HR SSC $>$ are very bright.

- The employees of the $<$ HR SSC $>$ are experts in their particular jobs and functions.

- The employees of the $<$ HR SSC $>$ are very well able to develop new ideas.

Social capital of the HRM service provider

- The employees of the $<$ HR SSC $>$ mutually share relevant information about the business units and end-users that the $<$ HR SSC $>$ serves.

- The employees of the $<$ HR SSC $>$ exchange ideas with each other.

- The employees of the $<$ HR SSC $>$ share information and learn from each other.

- The employees of the $<$ HR SSC $>$ tune a lot into each other.

- The employees of the $<$ HR SSC $>$ share much knowledge among each other.

\section{Organizational capital of the HRM service provider}

- Much of the knowledge in the < HR SSC $>$ is documented in manuals, process descriptions, (knowledge) databases, information technologies, etc.

- The $<$ HR SSC $>$ 's culture contains many valuable ideas, service delivery principles and ways of providing HR services.

- The $<$ HR SSC $>$ embeds much of its knowledge in systems and processes.

- The $<$ HR SSC $>$ standardized much of its processes.

- The $<$ HR SSC $>$ has information technologies which are well tailored to the specific situation of the $<$ HR SSC $>$ at its disposal (e.g. for selfservices, back office administrations, and handling calls).

- The < HR SSC > records vital knowledge and information to prevent loss in the event of (key) people leaving the organization.

Consumer human capital of the worker

- I know precisely where to make requests concerning personnel and payroll services (e.g. application for leave, declare travel expenses, requesting study facilities, life-course saving scheme).

- I always know which steps to follow in making requests concerning personnel and payroll services (online or on paper).

- I know precisely how my personal details (e.g. private address or bank account number) can be updated if they change.

- I know precisely whom to turn to when I have a problem with my personnel services.

- I know precisely where I can find or obtain information on employment conditions.

- I am always able to clearly explain my HR-related problems to an HR professional.

- I am fully able to solve my HR-related problems or get an answer to my question, together with an HR professional. 


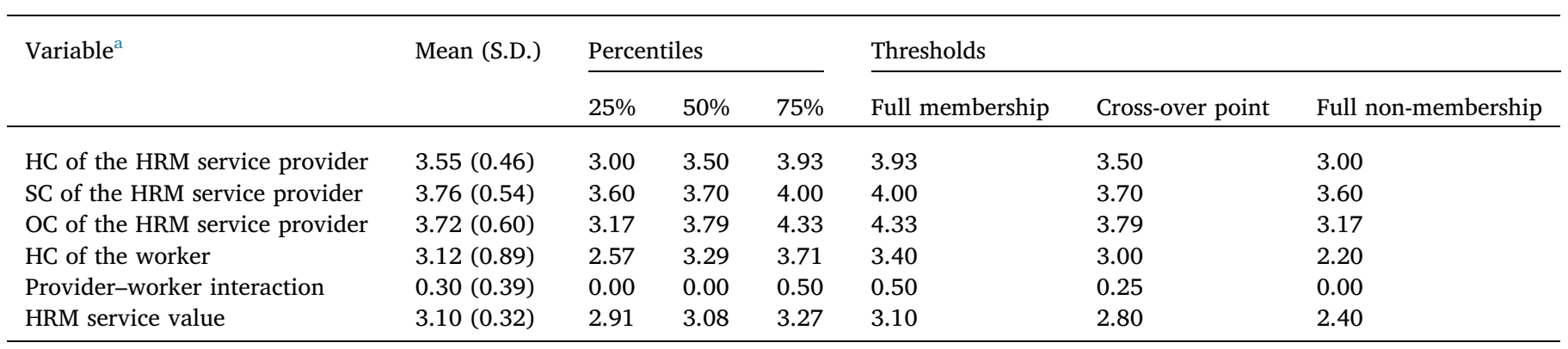

${ }^{\mathrm{a}} \mathrm{HC}=$ human capital, SC $=$ social capital, OC $=$ organizational capital.

\section{Rationale for calibration}

We relied on empirical evidence in the form of percentiles, as well as theoretical knowledge, to determine the three calibration thresholds (see table above).

\section{Intellectual capital of the HRM service provider}

The threshold values for the human, social and organizational capital of the HRM service provider are based on the percentiles. Theoretical knowledge supports the relative values of these thresholds. When establishing a centralized HRM service provider, organizations heavily invest in organizational capital in terms of redesigning and optimizing processes (Meijerink \& Bondarouk, 2013), as well as developing information technologies, such as HR portals and self-services (Farndale et al., 2009). Furthermore, organizations rely on centralized HRM service providers with the purpose to locate professionals centrally and, hence, increase social capital through increased knowledge exchange (Cooke, 2006). Despite these advantages, centralized HRM service providers are shown to face problems with respect to HR professional competences that either have too specialized knowledge and skills, outdated expertise or lack required communication skills (Cooke, 2006; Meijerink \& Bondarouk, 2013). Therefore, the thresholds for human capital are lower than those for organizational and social capitals. Finally, these thresholds are congruent with means for HR professional competences (mean $=3.58$, Boselie \& Paauwe, 2005) and capabilities (mean = 3.53, Sumelius, Björkman, \& Smale, 2008). As such, we are confident that the selected thresholds reflect sufficiently the degrees of the intellectual capital set memberships.

\section{Consumer human capital of the worker}

We decided to adopt lower thresholds than those suggested by the percentiles for worker human capital. First, because workers are shown to be too optimistic about their self-efficacy, especially those from Europe where this study was conducted (Schwarzer, Bäßler, Kwiatek, Schröder, \& Zhang, 1997). Second, because workers are not HR professionals and have been shown to have difficulties with consuming centralized HRM services (Cooke, 2006; Meijerink \& Bondarouk, 2013). This implies that the thresholds set for worker human capital should be lower than those for HR professionals. Finally, we found that the average consumer human capital score, measured as perceived self-efficacy by consumers, lies between 3.21 (McKee et al., 2006) and 3.41 (Van Beuningen et al., 2009). Given that these scores were obtained from consumers which regularly consume selected services (e.g. business students having to make online investment decisions; Van Beuningen et al., 2009), in comparison to workers who irregularly consume HR services, we decided to lower the worker human capital thresholds by approximately 0.30 points (equivalent to the difference between the general highest mean of perceived customer self-efficacy found in the literature $(=3.41)$ and our sample mean $(=3.12)$ ).

\section{Provider-worker interaction}

We relied on an index scale for measuring provider-worker interaction that consists of two items representing two different types of interaction. As such, workers could score a $0.00,0.50$ or 1.00 for provider-worker interaction. Given that the last two scores indicate the presence of some interaction, we decided to set the threshold for full membership at 0.50 and for non-membership at 0.00 . In other words, workers are assigned membership of a crisp set: (0.00) worker does not interact with HRM service provider or (1.00) worker does interact with the HRM service provider.

\section{HRM service value}

The value of centralized HRM services is considered a hygiene factor that decreases satisfaction when performed inadequately, but does not result in extreme satisfaction when performed perfectly (Boselie \& Paauwe, 2005). Therefore, as with worker human capital, we took the highest mean score for HR service value found in the literature (mean $=3.1$; Gilbert et al., 2011) as the threshold for full membership in high HR service value. We took the value that represents maximum ambiguity for the cross-over point which is 2.8 (in terms of academic criteria, this represents the sufficient/ insufficient threshold of 5.6 on a scale from 1 to 10). We took the difference between the other two thresholds subtracted from the cross-over point: $2.4(=2.80-(3.10-2.80))$ to determine the full non-membership threshold.

\section{References}

Auh, S., Bell, S. J., McLeod, C. S., \& Shih, E. (2007). Co-production and customer loyalty in financial services. J. Retail. 83(3), 359-370.

Ballantyne, D., \& Varey, R. J. (2006). Creating value-in-use through marketing interaction: The exchange logic of relating, communicating and knowing. Mark. Theory, 6(3), 335-348.

Barney, J. B., \& Clark, D. N. (2007). Resource-based theory: Creating and sustaining competitive advantage. Oxford, UK: Oxford University Press.
Biemans, P. J. (1999). Professionalisering van de Personeelsfunctie. Een Empirisch Onderzoek bij Twintig Organisaties. Delft: Eburon.

Blocker, C. P. (2011). Modeling customer value perceptions in cross-cultural business markets. J. Bus. Res. 64(5), 533-540.

Bondarouk, T., Ruel, H., \& van der Heijden, B. (2009). E-HRM effectiveness in a public sector organization: A multi-stakeholder perspective. International Journal of Human Resource Management, 20(3), 578-590.

Boselie, P., \& Paauwe, J. (2005). Human resource function competencies in European companies. Pers. Rev. 34(5), 550-566.

Bowman, C., \& Ambrosini, V. (2007). Firm value creation and levels of strategy. Manag. 
Decis. 45(3), 360-371.

Cooke, F. L. (2006). Modeling an HR shared service center: Experience of an MNC in the United Kingdom. Hum. Resour. Manag. 45(2), 211-227.

Cronin, J. J., \& Taylor, S. A. (1992). Measuring service quality: A reexamination and extension. J. Mark. 56(3), 55-68.

Delery, J. E. (1998). Issues of fit in strategic human resource management: Implications for research. Hum. Resour. Manag. Rev. 8, 289-310.

Delery, J. E., \& Doty, D. H. (1996). Modes of theorizing in strategic human resource management: Tests of universalistic, contingency, and configurational performance predictions. Acad. Manag. J. 39(4), 802-835.

Edgar, F., \& Geare, A. (2014). An employee-centred analysis: Professionals' experience and reactions to HRM. International Journal of Human Resource Management, 25(5), 673-695.

Farndale, E., Paauwe, J., \& Hoeksema, L. (2009). In-sourcing HR: Shared service centres in The Netherlands. International Journal of Human Resource Management, 20(3), 544-561.

Fiss, P. C. (2007). A set-theoretic approach to organizational configurations. Acad. Manag. Rev. 32(4), 1180-1198.

Fiss, P. C. (2011). Building better causal theories: A fuzzy set approach to typologies in organization research. Acad. Manag. J. 54(2), 393-420.

Fryberg, A., \& Jüriado, R. (2009). What about interaction? Networks and brands as integrators within service-dominant logic. J. Serv. Manag. 20(4), 420-432.

Gilbert, C., De Winne, S., \& Sels, L. (2011). The influence of line managers and HR de partment on employees' affective commitment. International Journal of Human Resource Management, 22(8), 1618-1637.

Gouthier, M., \& Schmid, S. (2003). Customers and customer relationships in service firms: The perspective of the resource-based view. Mark. Theory, 3(1), 119-143.

Gresov, C., \& Drazin, R. (1997). Equifinality: Functional equivalence in organization design. Acad. Manag. Rev. 22(2), 403-428.

Grönroos, C. (2011). A service perspective on business relationships: The value creation, interaction and marketing interface. Ind. Mark. Manag. 40(2), 240-247.

Gummeson, E. (1998). Implementation requires a relationship marketing paradigm. $J$. Acad. Mark. Sci. 26(3), 242-249.

Gummesson, E. (2008). Extending the service-dominant logic: from customer centricity to balanced centricity. Journal of the Academy of Marketing Science, 36(1), 15-17.

Han, J., Chou, P., Chao, M., \& Wright, P. M. (2006). The HR competencies-HR effectiveness link: A study in Taiwanese high-tech companies. Hum. Resour. Manag. 45(3), 391-406.

Hansen, M. T., Nohria, N., \& Tierney, T. (1999). What is your strategy for managing knowledge? Harv. Bus. Rev. 77(2), 106-116.

Hofman, E., \& Meijerink, J. G. (2015). Platform thinking for services: The case of human resources. Serv. Ind. J. 35(3), 115-132.

Hornung, S., Rousseau, D. M., \& Glaser, J. (2008). Creating flexible work arrangements through idiosyncratic deals. J. Appl. Psychol. 93(3), 655-664.

Jaakkola, E., \& Hakanen, T. (2013). Value co-creation in solution networks. Ind. Mark. Manag. 42(1), 47-58.

James, L. R., Demaree, R. G., \& Wolf, G. (1984). Estimating within-group interrater reliability with and without response bias. J. Appl. Psychol. 69(1), 85-98.

Jiang, K., Chuang, C.-H., \& Chiao, Y.-C. (2015). Developing collective customer knowledge and service climate: The interaction between service-oriented high-performance work systems and service leadership. J. Appl. Psychol. 100(4), 1089-1106.

Jiang, K., Lepak, D. P., Hu, J., \& Baer, J. C. (2012). How does human resource management influence organizational outcomes? A meta-analytic investigation of mediating mechanisms. Academy of management Journal, 55(6), 1264-1294.

Katz, D., \& Kahn, R. L. (1978). The social psychology of organizations. New York: Wiley.

Kaufman, B. E. (2015). The RBV theory foundation of strategic HRM: Critical flaws, problems for research and practice, and an alternative economics paradigm. Hum. Resour. Manag. J. 25(4), 516-540.

LeBreton, J. M., \& Senter, J. L. (2008). Answers to 20 questions about interrater reliability and interrater agreement. Organ. Res. Methods, 11(4), 815-852.

Lepak, D. P., Liao, H., Chung, Y., \& Harden, E. E. (2006). A conceptual review of human resource management systems in strategic human resource management research. In J. J. Martocchio (Vol. Ed.), Research in personnel and human resources management.
Vol. 25. Research in personnel and human resources management (pp. 217-271).

Lepak, D. P., Smith, K. G., \& Taylor, M. S. (2007). Value creation and value capture: A multilevel perspective. Acad. Manag. Rev. 32(1), 180-194.

Liao, H., Toya, K., Lepak, D. P., \& Hong, Y. (2009). Do they see eye to eye? Management and employee perspectives of high-performance work systems and influence processes on service quality. J. Appl. Psychol. 94(2), 371.

Maatman, M., Bondarouk, T., \& Looise, J. K. (2010). Conceptualising the capabilities and value creation of HRM shared service models. Hum. Resour. Manag. Rev. 20(4), 327-339.

McKee, D., Simmers, C. S., \& Licata, J. (2006). Customer self-efficacy and response to service. J. Serv. Res. 8(3), 207-220.

Meijerink, J. G., \& Bondarouk, T. (2013). Exploring the central characteristics of HR shared services: Evidence from a critical case study in The Netherlands. International Journal of Human Resource Management, 24(3), 487-513.

Meijerink, J. G., Bondarouk, T., \& Lepak, D. P. (2016). Employees as active consumers of HRM: Linking employees' HRM competences with their perceptions of HRM service value. Hum. Resour. Manag. 55(2), 219-240.

Meijerink, J. G., Bondarouk, T. V., \& Looise, J. C. (2013). Value creation through HR shared services: Towards a conceptual framework. Pers. Rev. 42(1), 83-104.

Nahapiet, J., \& Ghoshal, S. (1998). Social capital, intellectual capital and the organizational advantage. Acad. Manag. Rev. 23(2), 242-266.

Priem, R. L. (2007). A consumer perspective on value creation. Acad. Manag. Rev. 32(1), 219-235.

Priem, R. L., Li, S., \& Carr, J. C. (2012). Insights and new directions from demand-side approaches to technology innovation, entrepreneurship, and strategic management research. J. Manag. 38(1), 346-374.

Ragin, C. C. (2008). Redesigning social inquiry: fuzzy sets and beyond. Chicago: University of Chicago Press.

Reed, K. K., Lubatkin, M., \& Srinivasan, N. (2006). Proposing and testing an intellectual capital-based view of the firm. J. Manag. Stud. 43(4), 867-893.

Renkema, M., Meijerink, J., \& Bondarouk, T. (2016). Advancing multilevel thinking and methods in HRM research. Journal of Organizational Effectiveness: People and Performance, 3(2), 204-218.

Ruta, C. D. (2009a). HR portal alignment for the creation and development of intellectual capital. Int. J. Hum. Resour. Manag. 20(3), 562-577.

Ruta, C. D. (2009b). HR portal alignment for the creation and development of intellectual capital. International Journal of Human Resource Management, 20(3), 562-577.

Schneider, B., \& Bowen, D. E. (1995). Winning the service game. Boston: Harvard Business School Press.

Schneider, B., White, S. S., \& Paul, M. C. (1998). Linking service climate and customer perceptions of service quality: Tests of a causal model. J. Appl. Psychol. 83(2), 150.

Schwarzer, R., Bäßler, J., Kwiatek, P., Schröder, K., \& Zhang, J. X. (1997). The assessment of optimistic self-beliefs: Comparison of the German, Spanish, and Chinese versions of the general self-efficacy scale. Appl. Psychol. 46(1), 69-88.

Sumelius, J., Björkman, I., \& Smale, A. (2008). The influence of internal and external social networks on HRM capabilities in MNC subsidiaries in China. International Journal of Human Resource Management, 19(12), 2294-2310.

Szulanski, G. (1996). Exploring internal stickiness: Impediments to the transfer of best practice within the firm. Strateg. Manag. J. 17(S2), 27-43.

Ulrich, D., Younger, J., \& Brockbank, W. (2008). The twenty-first-century HR organization. Hum. Resour. Manag. 47(4), 829-850.

Van Beuningen, J., De Ruyter, K., Wetzels, M., \& Streukens, S. (2009). Customer selfefficacy in technology-based self-service: Assessing between- and within-person differences. J. Serv. Res. 11(4), 407-428.

Vargo, S. L., \& Lusch, R. F. (2008). Service-dominant logic: Continuing the evolution. J. Acad. Mark. Sci. 36(1), 1-10.

Vargo, S. L., Maglio, P. P., \& Akaka, M. A. (2008). On value and value co-creation: A service systems and service logic perspective. Eur. Manag. J. 26(3), 145-152.

Wildes, V. J., \& Parks, S. C. (2005). Internal service quality: Marketing strategies can help to reduce employee turnover for food servers. International Journal of Hospitality \& Tourism Administration, 6(2), 1-27.

Youndt, M. A., Subramaniam, M., \& Snell, S. A. (2004). Intellectual capital profiles: An examination of investments and returns. J. Manag. Stud. 41(2), 335-361. 